pharmacists that will be beneficial for all. We are quite sure that if the new system is implemented and the pharmacist is ready to be moulded into a new shape, practical application of these ideas can be achieved even in the least developed areas of Pakistan. It's better to try than to sit and wait for a miracle to happen.

\section{Fahad Saleem,}

B-Pharm, MPhil, MBA(HRM), PhD candidate, Discipline of Social and Administrative Pharmacy, School of Pharmaceutical Sciences, Universiti Sains Malaysia. E-mail: fahaduob@gmail.com

\section{Mohamed Azmi Ahmad Hassali,} Senior Lecturer/HOD, Discipline of Social and Administrative Pharmacy, School of Pharmaceutical Sciences, Universiti Sains Malaysia.

\section{Asrul Akmal Shafie}

Senior Lecturer, Discipline of Social and Administrative Pharmacy, School of Pharmaceutical Sciences, Universiti Sains Malaysia.

\section{REFERENCE}

1. Saleem F, Hassali AA, Shafie AA. Hypertension in Pakistan: time to take some serious action. Br J Gen Pract 2010; 60(575): 449-550.

DOI: 10.3399/bjgp10X515151

\section{Access to computed tomography}

Thomas et al's study into primary care access to computed tomography (CT) scanning ${ }^{1}$ (that found that the provision of open access CT for chronic headache reduced referrals to neurology by $88 \%$ in the scanned group) is a helpful addition to a sparsely researched area. Its premise and conclusion, however, ought not to be accepted without further consideration. The premise, that it is desirable to avoid referral to neurology, seems questionable as the aim must surely be to reach a diagnosis leading to treatment and, therefore, symptomatic improvement. A scan rarely did that. Of the 30 patients that had scans and were also referred to neurologists, 13 (43\%) had a consultation that lead to the diagnosis of a treatable condition, mainly migraine.

A scan may have stopped $88 \%$ of referrals to neurology but did the patients feel better? CT in patients without clinical indicators may have provided short-term relief for doctor and patient, but in the absence of definite neurological indications the study demonstrates the risk: $10.2 \%$ had incidental abnormalities and in $5 \%$ the scan triggered the referral. Greater CT availability would surely lead to greater usage, more incidental abnormalities, and more referrals; while the average GP requested fewer than two CT scans, one GP requested seven.

GPs may refer fewer chronic headaches if open access CT is available. However, our patients would benefit more from an informed and skilled consultation (whether in primary or secondary care) leading to diagnosis and treatment, than from a scan leading to incidental findings or, more commonly, nothing.

\section{Nick Hall,}

Department of Neurology, Gloucester Royal Hospital, Gloucester, GL1 3NN.

E-mail: longhallage@googlemail.com

\section{REFERENCE}

1. Thomas R, Cook A, Main G, et al. Primary care access to computed tomography for chronic headache. $\mathrm{Br} J$ Gen Pract 2010; 60(575): 426-429.

DOI: 10.3399/bjgp10X515160

\section{Detection of congenital heart disease in mid-Essex}

Congenital heart defects account for $3 \%$ of all infant deaths, with $18-25 \%$ of affected infants dying in the first year of life. Early (pre-symptomatic) identification helps improve outcome. ${ }^{1}$ Routine prenatal anomaly scans detect less than half of cardiac defects, ${ }^{2,3}$ hence detection after birth remains important. Only families with a high risk of congenital heart defects are offered foetal echocardiography.

The UK National Screening Committee's newborn screening policy comprises clinical examination at birth and at 6-8 weeks, with specific cardiac investigations for high-risk children. ${ }^{4}$

We conducted a 3-year retrospective study in mid-Essex evaluating the detection of congenital heart defects, during postnatal and 6-8 week examinations from September 2004 to August 2007 on 55 infants born in midEssex with a confirmed diagnosis of congenital heart defects. Twenty infants identified either antenatally or diagnosed while admitted in the neonatal unit for other indications or detected by active case finding because comorbid conditions were excluded.

Results showed an incidence of 5.5/1000 live-births/year. Postnatal examination detected sixteen (45\%) and GPs detected 13 infants (37\%) during the 6-8 week check. Six infants with significant congenital heart defects were missed on screening and presented later with symptoms. Cyanotic lesions accounted for just under a quarter of all cases $(23.6 \%)$. The most common acyanotic lesion was ventricular septal defect (29\%). Six infants with significant cardiac lesions were missed on screening and presented at varying ages from

9 days to 7 months of whom four presented with cyanosis. Although all these infants survived, the increased morbidity, use of emergency care resources, and parental stress could be avoided by early detection.

Newborn physical examination is increasingly done in the first 24-48 hours of life by doctors in training and midwives. A congenital heart defect is likely to be missed because signs and symptoms are uncommon in the first few days, infants may look well initially, cyanosis is difficult to detect, and femoral pulses may be felt even in left ventricular obstructive lesions as a result of shunting. 
Using echocardiogram as a screening tool would need enormous resources, would yield high false-positive rates, and is neither practical nor cost-effective. Results of a systematic review by Health Technology Assessment showed that clinical examination along with pulse oximetry had the highest detection rate with low false-positivity rates. ${ }^{4}$ The Pulseox study in the West Midlands is a large multicentre prospective study being conducted to assess diagnostic accuracy and cost-effectiveness of routine pulse oximetry to screen congenital heart defects. ${ }^{5}$

In our study, postnatal examination detected just under half of all infants with congenital heart defects. The 6-8 week infant check by GPs remains an important point of contact for patients as it detected more than a third of infants. The introduction of pulse oximetry as an aide to both these examination checks could increase detection.

\section{Acknowledgements}

We are grateful to the Department of Paediatrics St John's Hospital, Chelmsford for the help and support provided in conducting this study.

\section{Jogesh Kapadia,}

St John's Hospital, Paediatrics, Wood Street, Chelmsford, CM2 9BG.

E-mail: smitajogesh@yahoo.com

\section{RN Mahesh Babu,}

St John's Hospital, Paediatrics, Chelmsford.

\section{REFERENCES}

1. Knowles R, Griebsch I, Dezateux C, et al. Newborn screening for congenital heart defects: a systematic review and cost effective analysis. Health Technol Assess 2005; 9(44): 1-152, iii-iv.

2. Sharland G. Fetal cardiac screening: why bother? Arch Dis Child Fetal Neonatal Ed 2010; 95(1): F64-68.

3. Khoo NS, Van Essen P, Richardson M, et al. Effectiveness of prenatal diagnosis of congenital heart defects in South Australia: a population analysis 1999-2003. Aust N Z J Obstet Gynaecol 2008; 48(6): 559-563.

4. UK National Screening Committee. NHS Newborn and Infant Physical Examination Screening Programme (NIPE). London: NHS Newborn \& Infant Physical Examination Programme, 2010.

5. Ewer A. Pulse oximetry as a screening test for congenital heart disease in newborn babies. Southampton: National Institute for Health Research, 2010. http://www.hta.ac.uk/1624 (accessed 5 Jul 2010).

DOI: 10.3399/bjgp10X515179

\section{Are 'polysystems' for doctors or patients?}

Polysystems are an extension of the London polyclinics transformed into GPled health centres. Various studies debate the differences between models consisting of single large buildings and 'hub-and-spoke' models. Hutt et al ask the question: 'How is primary care best configured?"

The King's Fund quotes international examples from countries such as Russia and Cuba, arguing that it is more important to develop new ways of working than to construct buildings, and that new configurations are unlikely to be cheaper than existing systems. ${ }^{2}$ In addition, a report from Australia concludes that in the UK, existing medical practices are responsive and are able to meet community needs. ${ }^{3}$

In Italy, the national government is in the process of attempting to convince family doctors to sign new contracts requiring many additional medical duties without increased remuneration, as well as considering the creation of new megaaggregations of professionals within practices covering large populations. At the same time, the government is contemplating a shift of many services from secondary to primary care.

The reaction of associations of GPs is essentially negative. They predict a disruption of the existing structure into micro-groups, problems for patients having to travel considerable distances, and large institutions where there will be longer waiting times, confusion, and loss of doctor-patient continuity, possibly resulting in duplication of services.

Morgan and Beerstecker ${ }^{4}$ indicate that there is no evidence to suggest that very large practices can provide greater patient throughput or diversity of services than is available at the current average English practice. Therefore, a policy to create larger practices may not automatically lead to a transfer of work from secondary to primary care. Also, there is an upper threshold above which practice size simply creates spare capacity and untapped expertise.

It is most important to consider these data when we see, as at present, multiple national governments calling for new systems of governance for family medicine that involve top-down approaches not agreed to by primary caregivers, by secondary caregivers, or by patients themselves. ${ }^{5}$ It is dangerous for these changes to be pushed by politicians with the aim of achieving financial savings without considering what family medicine was, is, or will become. It is crucial that we remember the WONCA European Definition. ${ }^{6}$

Francesco Carelli, Professor of Family Medicine, EURACT Council Director of Communications, University of Milan. Email: carfra@tin.it

\section{REFERENCES}

1. Hutt P, Singh S, Modell M, et al. Polyclinics and polysystems: evolving ambiguity, evidence required. Br J Gen Pract 2010; 60(575): 400-401.

2. Imison C, Naylor C, Maybin B. Under one roof: will polyclinics deliver integrated care? London: King's Fund, 2008.

http://www.kingsfund.org.uk/document.rm?id=7699. (accessed 5 Jul 2010)

3. Powell Davies PG, McDonald J, Jeon Y-H, et al. Integrated primary health care centres and polyclinics: a rapid review. Sydney: Centre for Primary Health Care and Equity UNSW and Australian Primary Health Care Research Institute, 2009.

4. Morgan CL, Beerstecker HJ. Practice size and service provision in primary care: an observational study. $\mathrm{Br}$ J Gen Pract 2009, 59(560): 186-190.

5. Union Medici Italiani. Reaction to pre-agreement on a new contract with mega-aggregations. www.unionemedici.it/it/default.asp (accessed $5 \mathrm{Jul}$ 2010)

6. WONCA. The European Definition of General Practice/Family Medicine - 2005. http://www.woncaeurope.org/Definition\%20GPFM.htm (accessed 7 Jul 2010)

DOI: 10.3399/bjgp10X515188 